\title{
Effect of aerosol composition on the performance of low-cost optical particle counter correction factors
}

Leigh R. Crilley et al.

Correspondence to: Leigh R. Crilley (lcrilley@yorku.ca)

The copyright of individual parts of the supplement might differ from the CC BY 4.0 License. 

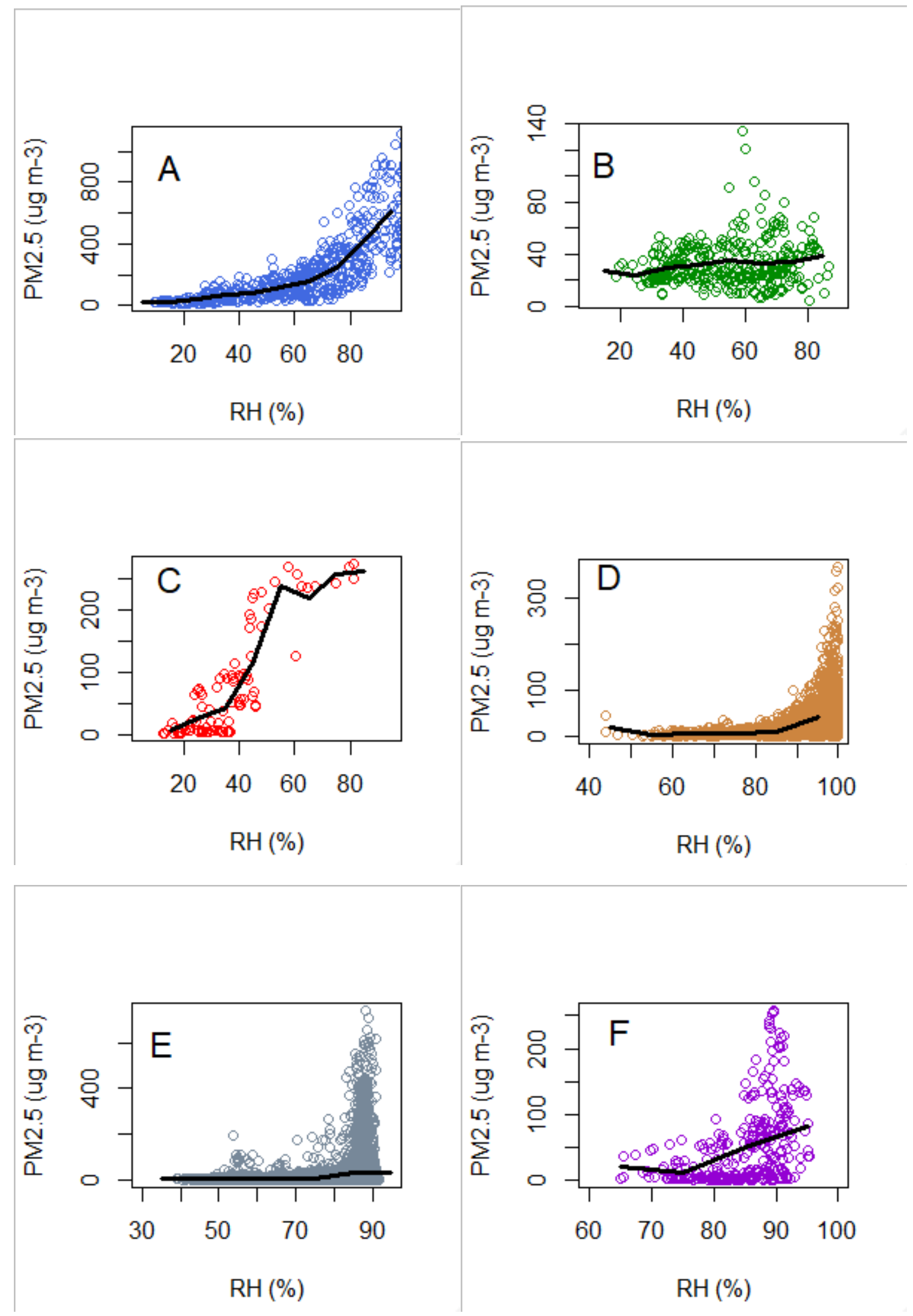

Figure S1: Plot of reported PM2.5 mass concentration by OPC-N2 against ambient RH for the whole measurement period in Delhi (A), Nairobi (B), Beijing (C), Bham BAQS (D), Nicaragua (E), Bham Tyburn (F). The black line is the mean reported PM2.5 mass concentration binned by RH (bin size $10 \% \mathrm{RH})$. Note the different $\mathrm{y}$ - and $\mathrm{x}$-axis scales. 


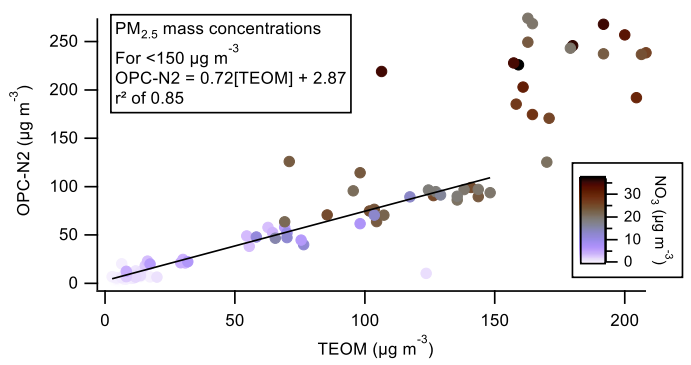

Figure S2: Uncorrected $\mathrm{PM}_{2.5}$ by OPC-N2 against TEOM measurements coloured by nitrate concentration in Beijing.
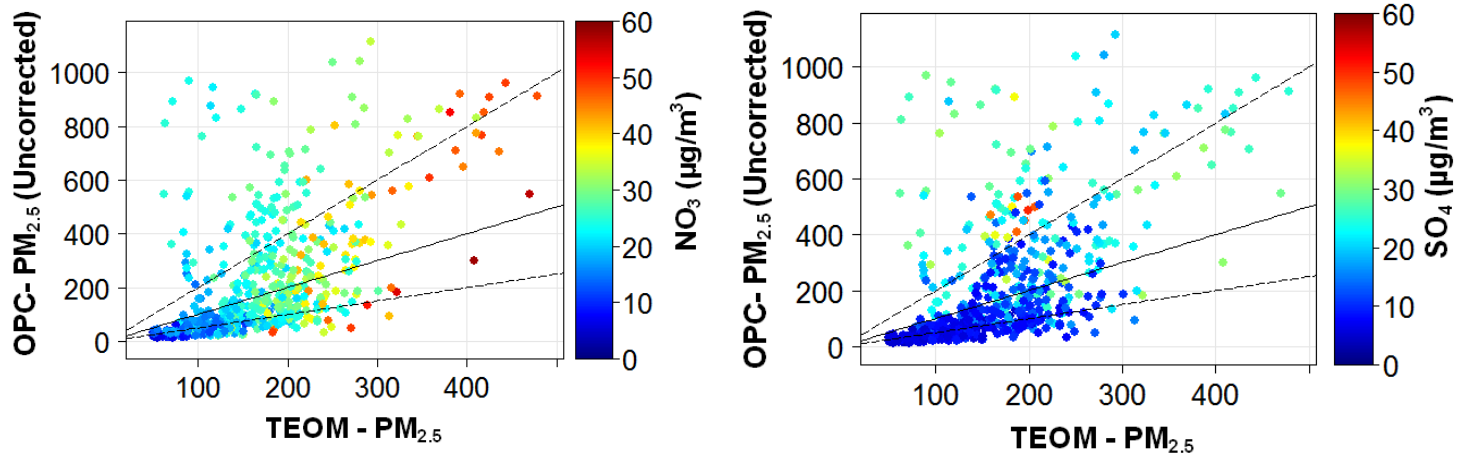

Figure S3: Uncorrected $\mathrm{PM}_{2.5}$ by OPC-N2 against TEOM measurements coloured by nitrate and sulphate concentration in Delhi. 


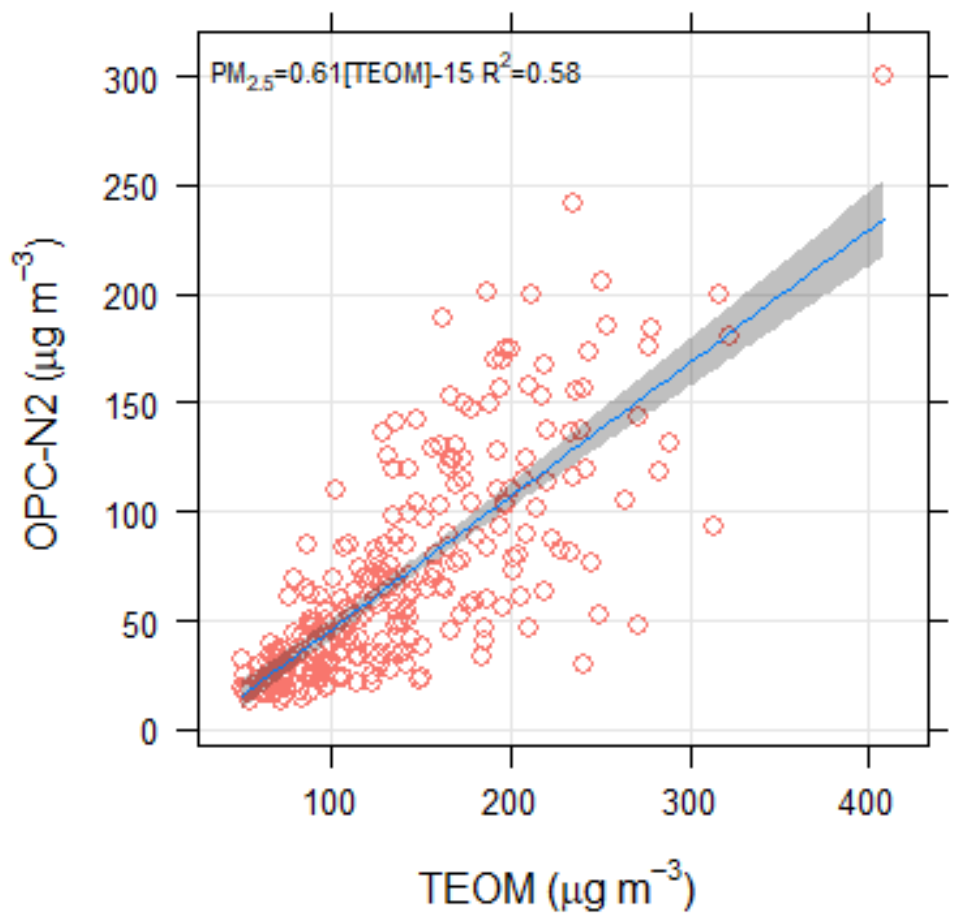

Figure S4: Scatterplot of uncorrected OC-N2 vs TEOM PM 2.5 measurements in Delhi for when the ambient RH was less than $60 \%$. 


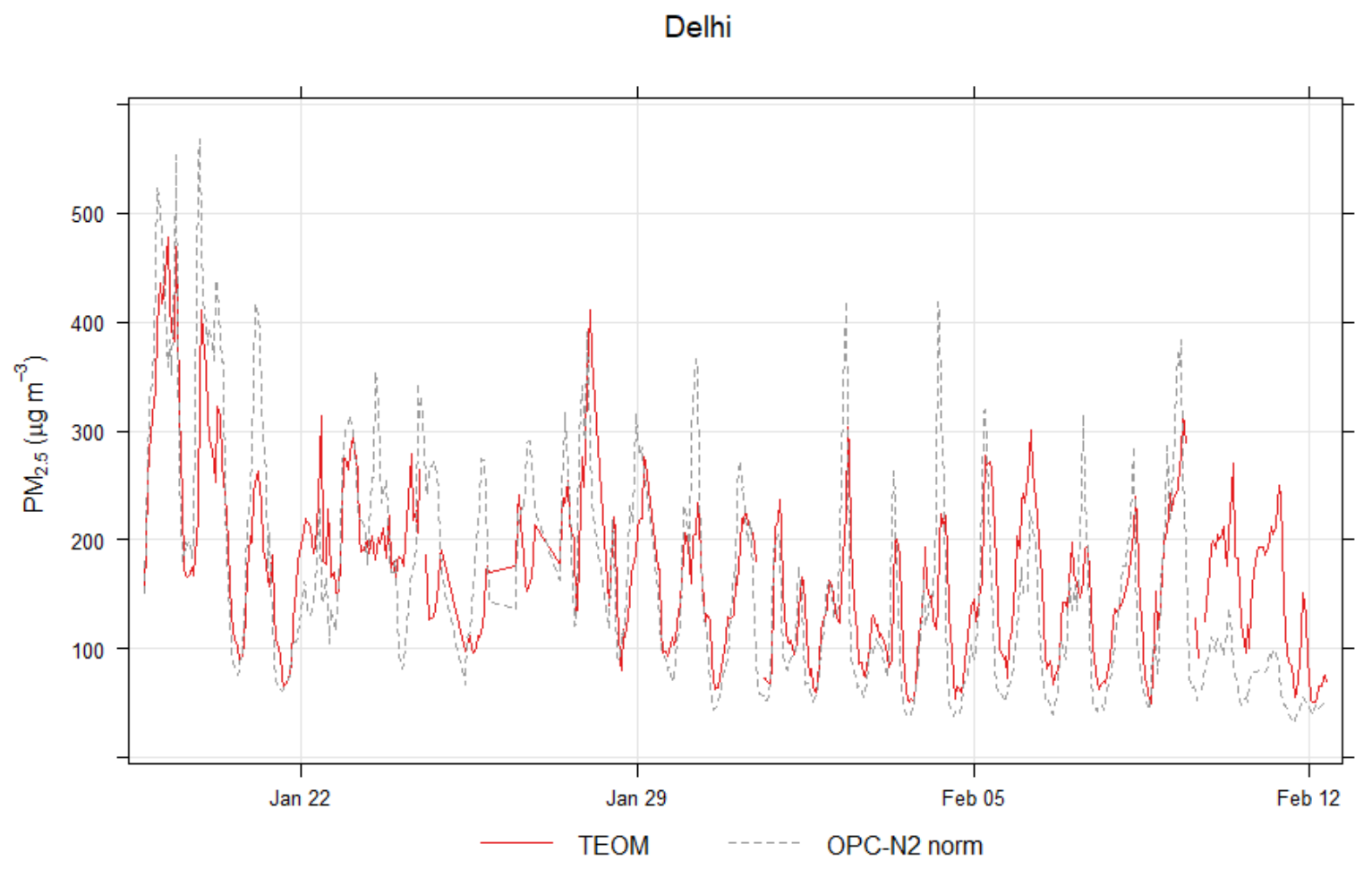

Figure S5: Time series of measured $\mathrm{PM}_{2.5}$ mass concentrations at Delhi by TEOM-FDMS and OPCN2 corrected by the two-stage approach (Section 3.1.1) 